CLINICAL STUDY

\title{
Detection of a complete autoimmune regulator gene deletion and two additional novel mutations in a cohort of patients with atypical phenotypic variants of autoimmune polyglandular syndrome type 1
}

\author{
Katarina Trebušak Podkrajšek ${ }^{1}$, Tatjana Milenković ${ }^{2}$, Roelof J Odink ${ }^{3}$, Hedi L Claasen-van der Grinten ${ }^{4}$, \\ Nina Bratanič ${ }^{5}$, Tinka Hovnik ${ }^{1}$ and Tadej Battelino ${ }^{1,5}$ \\ ${ }^{1}$ Centre for Medical Genetics, University Medical Centre, University Children's Hospital, Vrazov trg 1, SI-1000 Ljubljana, Slovenia, ${ }^{2}$ Mother and Child \\ Health Care Institute of Serbia, Belgrade, Serbia, ${ }^{3}$ Department of Pediatrics, Catharina Ziekenhuis, Eindhoven, The Netherlands, ${ }^{4}$ Department of Metabolic \\ and Endocrine Disease, University Medical Center St Radboud, Nijmegen, The Netherlands and ${ }^{5}$ Department of Pediatric Endocrinology, Diabetes and \\ Metabolism, University Medical Centre, University Children's Hospital, Ljubljana, Slovenia
}

(Correspondence should be addressed to K T Podkrajšek; Email: katarina.trebusak@kclj.si)

\begin{abstract}
Objective: Autoimmune polyglandular syndrome type 1 (APS-1) is characterised by multiple autoimmune diseases. Detection of autoimmune regulator (AIRE) gene mutations facilitates timely and precise diagnosis.

Design: AIRE mutation detection was performed in a cohort of 11 patients. Two did not meet clinical APS-1 criteria and several started with atypical presentation.

Methods: Sequencing and TaqMan genotyping were used to identify AIRE mutations. Complete AIRE deletion was confirmed and framed by real-time PCR, long-range amplification and analysis of the microsatellite markers.

Results: Seven different mutations were detected, three were novel: c.892G>A in exon 8, silent mutation c.462A $>\mathrm{T}$ in exon 3 most likely affecting splicing, and a complete deletion of a single AIRE allele ((?_68)_(1567-14_?)del). Novel (chronic otitis) and rare (systemic juvenile rheumatoid arthritis, autoimmune bronchiolitis, epilepsy) clinical presentations were observed.

Conclusions: AIRE mutation detection was valuable in the diagnostics of APS-1 in patients with atypical presentation. Chronic otitis media possibly broadened the cluster of APS-1 manifestations.
\end{abstract}

European Journal of Endocrinology 159 633-639

\section{Introduction}

Autoimmune polyendocrinopathy-candidiasis-ectodermal dystrophy (APECED; OMIM 240300) or autoimmune polyglandular syndrome type 1 (APS-1) is a rare autosomal recessive disorder, characterised by multiple autoimmune diseases and high levels of autoantibodies against antigens expressed in affected tissues. The classic triad includes chronic mucocutaneous candidiasis, hypoparathyroidism and Addison's disease. At least two of these disorders must be present in a patient to define the syndrome (1). APS-1 also affects other endocrine and non-endocrine organs resulting in diabetes mellitus, gonadal failure, autoimmune thyroid disease, autoimmune hepatitis, vitiligo, pernicious anaemia, exocrine pancreatic insufficiency, alopecia (2) and tubulointerstitial nephritis (3). Asplenia and squamous cell carcinoma can be present (4). The disease usually starts in childhood with additional components appearing throughout life (1).
Individual cases are described to have incomplete clinical presentation $(5,6)$.

In contrast to most other autoimmune diseases, APS-1 is associated with mutations of a single gene, designated autoimmune regulator (AIRE) $(7,8)$. AIRE protein regulates autoimmunity by promoting the ectopic expression of peripheral tissue-restricted antigens in medullary epithelial cells of the thymus (9). To date, more than 70 different mutations of the AIRE gene have been described and are distributed throughout the gene. Fifty-nine of them are listed in Human Gene Mutation Database (http://www.hgmd.cf.ac.uk), and 13 additional mutations are described in the literature $(6,10-13)$.

In this report, we present clinical and mutational characteristics of 11 APS-1 patients of different ethnical backgrounds. Three novel mutations, including a complete deletion of a single AIRE allele, and atypical clinical manifestations are discussed. 


\section{Subjects and methods}

\section{Patients}

Eleven APS-1 patients from nine unrelated Dutch, Serbian and Slovenian families were identified and included into the study. The study protocol was approved by the National Ethical Committee and written informed consent was obtained by all participants prior to the study.

\section{Mutational analyses of the AIRE gene}

All 14 exons, exon-intron boundaries and the promoter region ( -840 to start codon) of the AIRE gene were individually PCR amplified $(7,14)$. Amplicons were directly sequenced using the BigDye terminator cycle sequencing kit and ABI Prism 310 automated sequencer (Applied Biosystems, Norwalk, CT, USA) and compared with the normal AIRE sequence (GenBank accession no. AB006684).

Novel c. $892 \mathrm{G}>\mathrm{A}$ and c. $462 \mathrm{~A}>\mathrm{T}$ mutations were verified in 50 unrelated healthy controls by Custom TaqMan single nucleotide polymorphism (SNP) Genotyping Assay, designed by Applied Biosystems, and ABI Prism 7000 HT Sequence Detection System (Applied Biosystems, Foster City, CA, USA).

Copy number of c.967_979del13 AIRE allele was estimated using The SYBER Green Master Mix System (Applied Biosystems, Warrington, UK) and ABI Prism 7000 HT Sequence Detection System (Applied Biosystems). Primers flanking the c.967_979del13 mutation in exon 8 (5'-GGA GGC GGC CGT GAA T-3' and 5'-GGA CGA GTG TGC CGT GTG T- ${ }^{\prime}$ ) in $300 \mathrm{nM}$ concentrations and DNA in 20, 25 and $30 \mathrm{ng}$ input amount were used. Parameter cycle threshold $\left(C_{\mathrm{t}}\right)$ was determined and standard curves were generated by plotting logarithm of template concentration against the corresponding $C_{\mathrm{t}}$. The slope of the line was used to determine the efficiency of the target amplification $(E)$ using equation $E=\left(10^{-1 / \text { slope }}\right)-1$ (15).

AIRE was screened for deletions flanking multiple exons using long-range amplification of the complete gene with Expand Long Template PCR System (Roche) and primers previously used for amplification of exons 1 (forward) and 14 (reverse) respectively. The full length of the amplicon was $11938 \mathrm{bp}$ and was visualised using 0,6-agarose gel electrophoresis.

Additionally, TaqMan real-time PCR assay and relative quantification were performed to confirm that deletion is spanning the entire AIRE gene. RNaseP was used as reference single-copy gene (TaqMan RNaseP detection reagents; Applied Biosystems) to standardise the amount of template DNA added to the reaction. Before using the comparative $C_{\mathrm{t}}$ method, the validation experiment was performed demonstrating that the amplification efficiencies of target and reference alleles were approximately equal. In order to use the comparative $C_{\mathrm{t}}$ method, the absolute value of the slope of $\log$ input amounts versus $\Delta C_{\mathrm{t}}$ (difference between $C_{\mathrm{t}}$ of the target allele and the reference allele) was less then 0.1 . Copy number was calculated using the equation

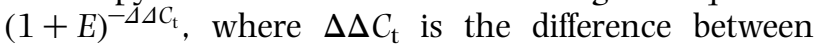
sample $\Delta C_{\mathrm{t}}$ and calibrator $\Delta C_{\mathrm{t}}$. As calibrator, the average $C_{\mathrm{t}}$ of five healthy control samples was used (16). Efficiency was calculated as previously stated (15). The samples were run in duplicate using exon 1 and 14 primers and probes as described in (17). Validation experiments were performed using 5, 2, 1 and $0.5 \mathrm{ng}$ input amounts of healthy control DNA.

Microsatellite length polymorphisms flanking AIRE were analysed at the DNA marker loci D21S1912, D21S1979, PFKL and D21S400 using primers described in Gene Databank, where one primer of a pair was labelled with fluorescein. Genomic DNA was PCR amplified and product sizes were estimated using ABI PRISM 310 automated sequencer and GeneMapper analysis software (Applied Biosystems).

\section{Results}

\section{Clinical characteristics of patients}

Clinical characteristics of individual APS-1 patients are summarised in Table 1. Patients were $8-23$ years old, 6 males and 5 females. All but two were fulfilling the clinical diagnostics criteria for APS-1. Patient 4/C was included due to chronic candidiasis since his second year of life. Patient 6/F was included due to Addison's disease and three additional minor manifestations. Nine patients had all three major manifestations, and two patients had only one. Additionally, 12 different minor manifestations were present.

In the Dutch patient 2/A, computed tomography (CT) scan showed calcifications in the subcortex and basal ganglia at the time of diagnosis of hypoparathyroidism. She subsequently presented with complex epilepsy that required treatment. Addison's disease was diagnosed at the age of 8 years requiring treatment with hydrocortisone in combination with 9 - $\alpha$-fludrocortison.

Serbian patient 5/E presented with recurrent episodes of high fever accompanied by rush and arthralgias at the age of 2 years and was diagnosed with systemic form of juvenile rheumatoid arthritis. Fever and arthralgias discontinued a year later. From the age of 3.5 to 8 years, she suffered from repeated episodes of cough, dyspnoea and mild bronchoconstriction. She had been treated for presumed asthma over 4 years without much improvement. According to the course of respiratory disease, autoimmune bronchiolitis was suspected. Treatment with prednisone led to marked improvement. Thereafter, she had no significant respiratory problems. Lung function tests were normal and prednisone was withdrawn. Hypoparathyroidism developed when she was 7.5 years old, adrenal failure at 8 years and ovarian failure at 12 years of age. 
Table 1 Clinical characteristics and AIRE genotype in analysed autoimmune polyglandular syndrome type 1 (APS-1) patients.

\begin{tabular}{|c|c|c|c|c|c|c|c|c|c|c|c|}
\hline \multirow[b]{2}{*}{ P/F } & \multirow[b]{2}{*}{ Sex } & \multirow[b]{2}{*}{ YOB } & \multicolumn{8}{|c|}{ Manifestations (age in years at diagnosis of component) } & \multirow[b]{2}{*}{ AIRE genotype } \\
\hline & & & $\mathrm{Hp}$ & A & MC & $\mathrm{Al}$ & ED & $\mathrm{Hg}$ & PA & Additional components & \\
\hline \multicolumn{12}{|l|}{ Dutch } \\
\hline $1 / \mathrm{A}$ & M & 1993 & & 2 & 3 & & 3 & & & $\begin{array}{l}\text { Chronic/tension head- } \\
\text { aches, allergy }\end{array}$ & $\begin{array}{l}\text { c. [967_979del13]+ } \\
{[(? \mathbf{?} \text { 68)_(1567-14_?)del] }} \\
\text { p.[Cys322fs]+(0?) }\end{array}$ \\
\hline $2 / \mathrm{A}$ & $\mathrm{F}$ & 1992 & 5 & 6 & 7 & & 8 & 9 & & $\begin{array}{l}\text { Complex epilepsy, } \\
\text { hypothalamic-pituitary } \\
\text { dysfunction }\end{array}$ & 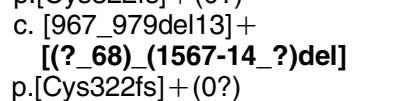 \\
\hline 3/B & M & 1996 & 6 & 8 & + & & & $?$ & & l & $\begin{array}{l}\text { c. }[62 \mathrm{CT}]+[967 \text { 979del13] } \\
\text { p. }[\text { Ala21Val }]+[\text { Cys322fs }]\end{array}$ \\
\hline \multicolumn{12}{|r|}{ 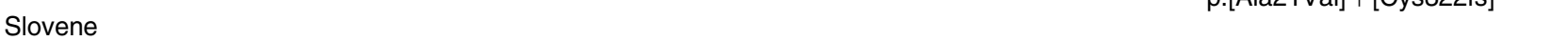 } \\
\hline $4 / \mathrm{C}$ & M & 1998 & & & 2 & & & & & l & $\begin{array}{l}\text { c.[21_43dup23]+[21_43dup23] } \\
\text { p.[Arg15fs]+[Arg15fs] }\end{array}$ \\
\hline \multicolumn{12}{|c|}{ Serbian } \\
\hline $5 / \mathrm{E}$ & $\mathrm{F}$ & 1987 & 7.5 & 8 & 11 & & & 12 & 17 & $\begin{array}{l}\text { Chronic otitis media with } \\
\text { effusion, asthma-like } \\
\text { dyspnoea, systemic } \\
\text { juvenile rheumatoid } \\
\text { arthritis }\end{array}$ & $\begin{array}{l}\text { c. }[892 G>A]+[769 \mathrm{C}>\mathrm{T}] \\
\text { p. }[\text { Glu298Lys }]+[\text { Arg257X] }\end{array}$ \\
\hline $6 / F$ & M & 1996 & & 11 & & 2.5 & 2 & & & Malabsorption (2) & $\begin{array}{l}\text { c. }[462 A>T]+[769 C>T] \\
\text { p. }(=)+[\operatorname{Arg} 257 X]\end{array}$ \\
\hline $7 / G$ & $\mathrm{~F}$ & 2000 & 5 & 4 & 1 & & & & & Vitiligo (1) & $\begin{array}{l}\text { c. }[769 C>T]+[769 C>T] \\
\text { p. }[\text { Arg257X] }]+[\operatorname{Arg} 257 X]\end{array}$ \\
\hline 8/H & $\mathrm{F}$ & 1986 & 15 & 16 & 5 & & & & 16 & Chronic hepatitis (15) & $\begin{array}{l}\text { c. }[769 \mathrm{C}>\mathrm{T}]+[769 \mathrm{C}>\mathrm{T}] \\
\text { p. }[\operatorname{Arg} 257 \mathrm{X}]+[\operatorname{Arg} 257 \mathrm{X}]\end{array}$ \\
\hline $9 / 1$ & M & 1988 & 9 & 11 & 6 & & & & & Malabsorption (9) & $\begin{array}{l}\text { c. }[769 \mathrm{C}>\mathrm{T}]+[769 \mathrm{C}>\mathrm{T}] \\
\text { p. }[\operatorname{Arg} 257 \mathrm{X}]+[\operatorname{Arg} 257 \mathrm{X}]\end{array}$ \\
\hline $10 / J$ & $\mathrm{~F}$ & 1985 & 9 & 10 & 10 & 10 & & 18 & & / & $\begin{array}{l}\text { c. }[769 C>T]+[769 C>T] \\
\text { p. }[\operatorname{Arg} 257 X]+[\operatorname{Arg} 257 X]\end{array}$ \\
\hline $11 / \mathrm{J}$ & M & 1989 & 13 & 14 & 11 & 13 & & & 10 & Malabsorption (11) & $\begin{array}{l}\text { c. }[769 \mathrm{C}>\mathrm{T}]+[769 \mathrm{C}>\mathrm{T}] \\
\text { p. }[\operatorname{Arg} 257 \mathrm{X}]+[\operatorname{Arg} 257 \mathrm{X}]\end{array}$ \\
\hline
\end{tabular}

P, patient; F, family; YOB, year of birth; Hp, hypoparathyroidism; A, Addison's disease; MC, mucocutaneous candidiasis; Al, alopecia; ED, ectodermal dystrophy; Hg, hypogonadism; PA, pernicious anaemia; mutations are described as cDNA change of AIRE ORF (GenBank accession no. AB006682) and as affecting the protein coding sequence; novel mutations are presented in bold; numbers represent the age in years at the diagnosis.

Chronic otitis media with effusion was diagnosed when she was 16.5 years old and lasted for 8 months despite the standard treatment. Pernicious anaemia developed when she was 17 years old.

\section{Mutational analyses}

Seven different mutations of the AIRE gene were detected in 11 APS-1 patients, 3 of which were novel and so far not reported (Table 1). Mutations were named starting the numbering from the translation initiation AUG codon (GenBank accession no. AB006682), and as recommended by den Dunnen and Antonarakis (18). None of them was detected in 50 healthy control subjects.

The novel c.892G >A (p.Glu298Lys) mutation was detected in heterozygous state of maternal origin in patient 5/E (Fig. 1) and was located in exon 8 at the beginning of the first plant homeo domain (PHD).

The second novel mutation in patient $6 / \mathrm{F}$ was a substitution of A with $\mathrm{T}$. It is retaining proline at position 154 (Fig. 2). Due to its position at the second nucleotide before the end of exon 3 , the mutation was suspected to affect proper splicing. Two splice-site prediction programs were used, namely Neural Network Splice Site Prediction Tool and FGENESH_SPL, to evaluate the quality of the altered donor site. The wild-type sequence resulted in predicted scores, 0.79 and 0.47 respectively. By contrast, the altered sequence was not recognised as the donor site by any of the used prediction programs.

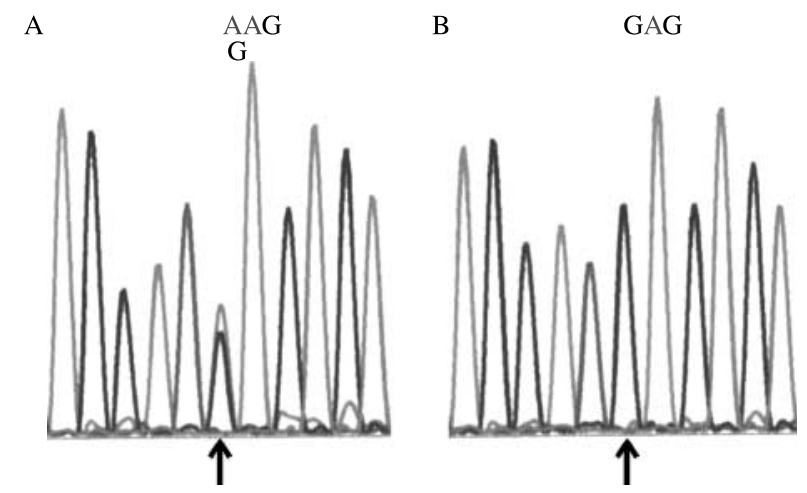

Figure 1 (A) A novel heterozygous c.892G >A (p.Glu298Lys) mutation and $(B)$ normal exon 8 sequence in patient $5 / E$. 


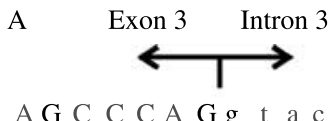

A G C C A G g t a c

$\mathrm{T}$

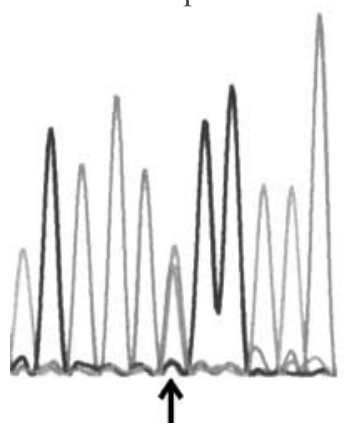

B

AG C C C A G g a c

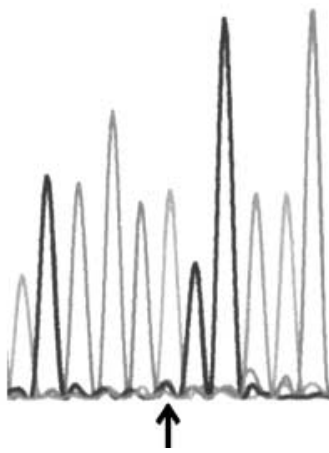

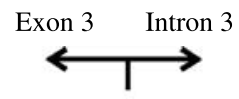

Figure 2 (A) A novel heterozygous c.462A $>$ T $(p .=)$ mutation and (B) normal exon $3 /$ intron 3 boundary in patient 6/F.

Unusual inheritances of the c.967_979del13 mutation and AIRE SNPs were observed in family A (Table 2). Patients $1 / \mathrm{A}$ and $2 / \mathrm{A}$ did not share the same c.967_979del13 allele with their fathers. They also did not share SNPs in exons 5, 7 and 10 and introns 7 and 9. Existence of a major AIRE gene deletion resulting in the loss of at least exons 5-10 in one allele was suggested. The deletion of one allele was confirmed by SYBER Green real-time amplification and detection of exon 8 AIRE allele in different concentrations of DNA. The standard curves showed parameter $C_{\mathrm{t}}$ to be one cycle higher in the father and both patients than in the mother in all DNA concentrations (Fig. 3A). Efficiency of the amplification was $67 \%$ in patient $1 / A, 66 \%$ in patient $2 / \mathrm{A}, 67 \%$ in the father and $70 \%$ in the mother. Therefore, the difference in the $C_{t}$ was not due to contamination of the template. Amplification pattern of the complete AIRE gene was the same in all family members and in the healthy control subject, excluding deletion limited to only a few exons. TaqMan real-time assay was performed to confirm that the deletion was spanning the entire AIRE gene. The validation experiment had fulfilled the criteria and comparative $C_{\mathrm{t}}$ method was applied. Since efficiencies derived from the standard curves were less than $100 \%$, extended formula $(1+E)^{-\Delta \Delta C_{\mathrm{t}}}$ was used. Factor $(1+E)^{-\Delta \Delta C_{\mathrm{t}}}$ (relative to
RNaseP) was around 0.5 in patients and their father and 1 in their mother (Table 3) confirming the existence of the one-allele deletion in patients $1 / \mathrm{A}$ and $1 / \mathrm{B}$ and their father, but not in their mother. The deletion was spanning at least from the annealing sites of the primers from position c. 68 in exon 1 and to the position c.1567-14 in intron 13. The deletion was also evident from amplification curves where AIRE allele amplicon $\mathrm{C}_{\mathrm{t}}$ 's were one cycle higher in patients and their father as in their mother (Fig. 3B). By contrast, RNaseP $C_{t}$ 's were alike. Microsatellite markers D21S1979, PFKL and D21S400 were not informative since all the family members carried the same allele. Analyses of microsatellite marker D21S1912 had shown inheritance of $208 \mathrm{bp}$ paternal and $204 \mathrm{bp}$ maternal alleles. The deletion at this position, $150 \mathrm{~kb}$ distant from the AIRE gene, was no longer present.

\section{Discussion}

APS-1 presents as an extremely variable combination of autoimmune endocrine and non-endocrine disorders. The current clinical diagnosis is based on the presence of two of three of the commonest clinical manifestations and allows early recognition of only a minority of new cases (4). In this report, patients $4 / \mathrm{C}$ and $6 / \mathrm{F}$ had a clinical picture that did not meet the clinical diagnostics criteria, but were diagnosed with having APS-1 after detection of an AIRE mutation. In addition, patient 5/E had extremely unusual clinical presentation with three atypical components. Reports describing less typical clinical cases with late onset (13) or unusual presentation are emerging $(4-6,13,19)$, supporting the idea that the diagnostics criteria for APS-1 should be redefined (6). Additionally, diagnostics flow charts defining which patients should be subject to genetic analyses are needed.

Patient 6/F started with malabsorption, ectodermal dystrophy and vitiligo at the age of 2 years, and developed Addison's disease as the only major component when he was 11 , fulfilling the criteria for APS-4 rather than APS-1. At that time, mutation detection was performed confirming APS-1. The patient was compound heterozygote for the common Finnish c.769C $>\mathrm{T}(\operatorname{Arg} 257 \mathrm{X})$ mutation and a novel

Table 2 Inheritance of the c.967_979del13 mutation, AIRE single nucleotide polymorphisms (SNPs) and a major AIRE deletion c.(?_68)+ (1567-14_?)del in family A (1/A and 2/A are APS-1 patients; M, mother; F, father).

\begin{tabular}{|c|c|c|c|c|c|c|}
\hline & $\begin{array}{l}\text { c.588 C }>\mathbf{T} \\
\text { (exon 5) }\end{array}$ & $\begin{array}{l}\text { c.834C }>\mathbf{G} \\
\text { (exon 7) }\end{array}$ & $\begin{array}{l}\text { c.879+101G }>\mathbf{A} \\
\text { (intron } 7 \text { ) }\end{array}$ & AIRE mutation & $\begin{array}{l}\text { c. } 995+6 \mathbf{G}>\mathbf{A} \\
\text { (intron 9) }\end{array}$ & $\begin{array}{l}\text { c.1197T }>\text { C } \\
\text { (exon 10) }\end{array}$ \\
\hline $1 / \mathrm{A}$ & $\mathrm{T}$ & C & $\mathrm{G}$ & $\begin{array}{l}\text { c. [967_979del13]+ [(?_68) } \\
\quad \text { (1567-14_?)del] }\end{array}$ & $\mathrm{G}$ & $\mathrm{C}$ \\
\hline $2 / \mathrm{A}$ & $\mathrm{T}$ & C & G & 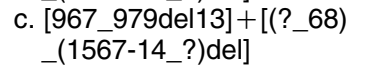 & $\mathrm{G}$ & $\mathrm{C}$ \\
\hline$M$ & $\mathrm{~T} / \mathrm{C}$ & $\mathrm{C} / \mathrm{C}$ & $\mathrm{G} / \mathrm{G}$ & c. $\left[967 \_979\right.$ del13]+ [=] & $\mathrm{G} / \mathrm{G}$ & $\mathrm{C} / \mathrm{T}$ \\
\hline $\mathrm{F}$ & C & $\mathrm{G}$ & A & $\begin{array}{l}\text { c. }[=]+\left[\left(? \_68\right) \_\left(1567-14 \_?\right)\right. \\
\text { del }]\end{array}$ & A & $\mathrm{T}$ \\
\hline
\end{tabular}


A

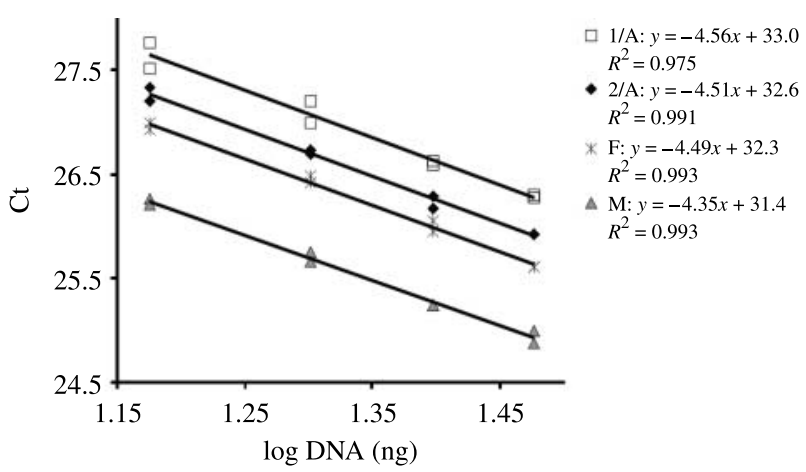

B

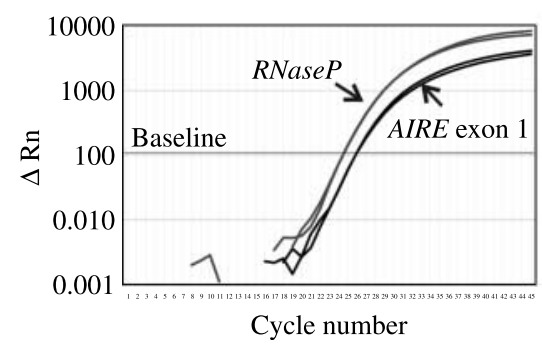

Mother

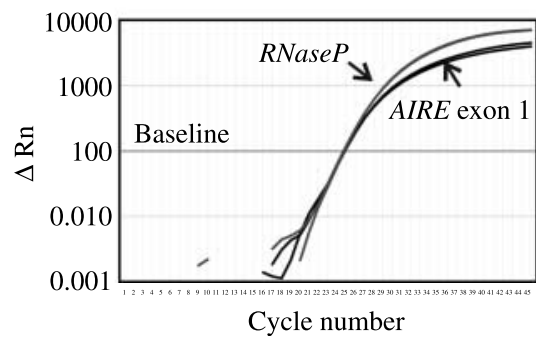

Figure 3 Real-time PCR detection of a complete single-allele AIRE deletion in family $A$. (A) SYBER green assay: logarithm of DNA concentration plotted against the corresponding $C_{\mathrm{t}}$ (1/A in 2/A are APS-1 patients; $M$, mother; $F$, father). (B) TaqMan assay: amplification plot of exon 1 AIRE allele and $R$ Nase $P$ allele in patient $1 / \mathrm{A}$ and his mother.
c.462A $>$ T (p. $(=))$ mutation. The c.462A $>$ T mutation emerged de novo in this patient. It was located at the end of exon 3 and was part of the classical donor splice site (20). Although the c.462A $>$ T mutation was a silent mutation, it was highly likely to affect proper splicing as was suggested by splice-site prediction tools. Eight different mutations are so far reported to affect splicing, all of them being intronic $(12,13,21-25)$. The c. $462 \mathrm{~A}>\mathrm{T}$ mutation was the first silent exonic mutation predicted to be pathogenic in APS-1. Therefore, exonic nucleotide substitutions in the AIRE gene not resulting in an amino acid substitution should be considered as potentially pathogenic.

Chronic candidiasis was the only manifestation present in patient $4 / C$. Since candidiasis developed in his early childhood and is frequently the first manifestation of APS-1 $(1,26)$, the patient was included in the study. Homozygous mutation c.21_43dup23 (R15fs) confirming the diagnosis was found. The c.21_43dup23 mutation was so far reported only in the heterozygous state in one Slovenian (12) and one Hungarian patient (27). Chronic candidiasis detected in early childhood should always be considered a possible manifestation of APS-1. The correct diagnosis is important for the prognosis and anticipation of additional manifestations, especially an adrenal crisis.

A novel c.892G $>$ A (p.Glu298Lys) mutation was detected in patient $5 / \mathrm{E}$. Due to its position, the mutation was expected to disrupt the first PHD domain of the AIRE protein. At least five additional missense mutations in this domain are reported $(19,24,28$, 29). Two of them (c.932G $>A$ and c.977C $>A$ ) are shown to alter intracellular localisation of the protein AIRE and to reduce its stimulating effect on transcription (28). The c.892G $>A$ in heterozygosity with the c.769C $>\mathrm{T}(\operatorname{Arg} 257 \mathrm{X})$ mutation was associated with an extremely unusual clinical presentation with three very rare components (Table 1 ).

Patient 5/E suffered from a systemic form of juvenile rheumatoid arthritis. This is an unusual component, since the pattern of autoimmune diseases in APS-1 shows organ-specific autoimmunity. So far, only two adult patients with rheumatoid arthritis (30) and one with pauciarticular juvenile rheumatoid arthritis (23) are described as having APS-1. Patient 5/E also presented with an asthma-like dyspnoea, which is a rare component of APS-1. One patient was reported to have fatal obstructive lung disease (31) and one bronchitis obliterans organising pneumonia (4). Therefore, autoimmune bronchiolitis should be considered as a rare but potentially life-threatening component of

Table 3 TaqMan real-time assay derived factor $(1+E)^{-\Delta \Delta C_{t}}$ in family $A$ (1/A and 2/A are APS-1 patients; $M$, mother; $F$, father) in exons 1 and 14 (E, efficiency; $\Delta \Delta C_{\mathrm{t}}$, difference between sample $\Delta C_{\mathrm{t}}$ and calibrator $\left.\Delta C_{\mathrm{t}}\right)$.

\begin{tabular}{lcc}
\hline & \multicolumn{2}{c}{$(1+\mathrm{E})^{-\Delta \Delta \mathrm{C}_{\mathrm{t}}}$} \\
\cline { 2 - 3 } & Exon 1 $(E=1.28)$ & Exon 14 $(E=1.11)$ \\
\hline $\mathrm{M} / \mathrm{A}$ & 0.44 & 0.52 \\
$\mathrm{~A} / \mathrm{A}$ & 0.48 & 0.65 \\
$\mathrm{M}$ & 1.31 & 1.11 \\
$\mathrm{~F}$ & 0.54 & 0.48 \\
\hline
\end{tabular}


APS-1, as suggested previously (32). In addition, this patient suffered from a chronic otitis media with effusion, which has, to our knowledge, not been previously reported in APS-1. Patients with calcified plaques in the tympanic membrane are not reported to suffer from repeated ear infections (1). The clinical manifestation presented in our patient might represent a novel minor component of the APS-1 and is possibly broadening the wide spectrum of APS-1 clinical manifestations.

All three Dutch patients had the heterozygous c.967_979del13 (Cys322fs) mutation previously described in this population $(7,28)$. Patient 3/B additionally had a rare c. $62 \mathrm{C}>\mathrm{T}$ (Ala21Val) mutation, so far described in only three patients from Sweden and North America (33). The Dutch siblings from family A additionally had a complete single-allele AIRE deletion spanning at least from exon 1 to intron 13 inherited paternally, as confirmed by real-time amplification. Similarly, AIRE gene copy number detection in the diagnostics of APS-1 is recently described in two Scandinavian APS-1 patients, where deletion was covering at least exons 2-8 (17). Another large deletion spanning exons 2-4 was described in two patients $(3,27)$. Large genomic deletions ranging from a single exon to a large chromosomal region can escape conventional mutation analysis, since normal allele PCR products can mask the deletion in the diseaserelated chromosome (34). Sequencing analysis in patients $1 / \mathrm{A}$ and $2 / \mathrm{B}$ were misleading and showed homozygosity of c.967_979del13 mutation. Determination of the real AIRE genotype could be important, if carrier status of their siblings or relatives had to be determined. Thus, the screening method for larger deletions can be a useful tool in the genetics diagnostics of APS-1.

Patient 2/B had calcifications in the subcortex and basal ganglia and later presented with complex epilepsy. Previously, epilepsy was reported in one Spanish APS-1 patient (35).

The c.769C $>\mathrm{T}(\operatorname{Arg} 257 \mathrm{X})$ mutation was the predominant AIRE mutation in Serbian APS-1 patients (Table 1). It was present in all patients in at least the heterozygous state. The same was reported for Slovenian (12) and eastern European populations (27), suggesting the clustering of the mutation in this region.

In conclusion, three novel mutations, including a silent exonic mutation possibly affecting the splicing donor site and a complete deletion of a single AIRE allele, were described. AIRE gene mutation analyses proved useful in establishing the diagnosis in the patient with incomplete or unusual clinical presentation.

\section{Declaration of interest}

The authors declare that there is no conflict of interest that would prejudice the impartiality of this scientific work.

\section{Funding}

The study was supported in part by the Slovenian Research Agency grants no. J3-9663 and no. P3-0343.

\section{Acknowledgements}

We thank Mrs Jurka Ferran for her expert technical assistance.

\section{References}

1 Ahonen P, Myllarniemi S, Sipila I \& Perheentupa J. Clinical variation of autoimmune polyendocrinopathy-candidiasis-ectodermal dystrophy (APECED) in a series of 68 patients. New England Journal of Medicine 1990322 1829-1836.

2 Betterle C, Greggio NA \& Volpato M. Clinical review 93: autoimmune polyglandular syndrome type 1. Journal of Clinical Endocrinology and Metabolism 199883 1049-1055.

3 Ulinski T, Perrin L, Morris M, Houang M, Cabrol S, Grapin C, Chabbert-Buffet N, Bensman A, Deschenes G \& Giurgea I. Autoimmune polyendocrinopathy-candidiasis-ectodermal dystrophy syndrome with renal failure: impact of posttransplant immunosuppression on disease activity. Journal of Clinical Endocrinology and Metabolism 200691 192-195.

4 Perheentupa J. Autoimmune polyendocrinopathy-candidiasisectodermal dystrophy. Journal of Clinical Endocrinology and Metabolism $2006912843-2850$.

5 Boe AS, Knappskog PM, Myhre AG, Sorheim JI \& Husebye ES. Mutational analysis of the autoimmune regulator (AIRE) gene in sporadic autoimmune Addison's disease can reveal patients with unidentified autoimmune polyendocrine syndrome type I. European Journal of Endocrinology 2002146 519-522.

6 Buzi F, Badolato R, Mazza C, Giliani S, Notarangelo LD, Radetti G, Plebani A \& Notarangelo LD. Autoimmune polyendocrinopathycandidiasis-ectodermal dystrophy syndrome: time to review diagnostic criteria? Journal of Clinical Endocrinology and Metabolism 200388 3146-3148.

7 The Finnish-German APECED Consortium. An autoimmune disease, APECED, caused by mutations in a novel gene featuring two PHD-type zinc-finger domains. Autoimmune polyendocrinopathy-candidiasis-ectodermal dystrophy. Nature Genetics 199717 399-403.

8 Nagamine K, Peterson P, Scott HS, Kudoh J, Minoshima S, Heino M, Krohn KJ, Lalioti MD, Mullis PE, Antonarakis SE, Kawasaki K, Asakawa S, Ito F \& Shimizu N. Positional cloning of the APECED gene. Nature Genetics 199717 393-398.

9 Anderson MS, Venanzi ES, Klein L, Chen Z, Berzins SP, Turley SJ, von Boehmer H, Bronson R, Dierich A, Benoist C \& Mathis D. Projection of an immunological self shadow within the thymus by the aire protein. Science 2002298 1395-1401.

10 Lintas C, Cappa M, Comparcola D, Nobili V \& Fierabracci A. An 8 -year-old boy with autoimmune hepatitis and Candida onychosis as the first symptoms of autoimmune polyglandular syndrome (APS1): identification of a new homozygous mutation in the autoimmune regulator gene (aire). European Journal of Pediatrics $2007167949-953$.

11 Magitta F, Pura M, Wolff SB, Vanuga P, Meager A, Knappskog M \& Husebye ES. Autoimmune polyendocrine syndrome type $\mathrm{I}$ in Slovakia: relevance of screening patients with autoimmune Addison's disease. European Journal of Endocrinology 2008158 705-709.

12 Podkrajsek KT, Bratanic N, Krzisnik C \& Battelino T. Autoimmune regulator-1 messenger ribonucleic acid analysis in a novel intronic mutation and two additional novel AIRE gene mutations in a cohort of autoimmune polyendocrinopathy-candidiasis-ectodermal dystrophy patients. Journal of Clinical Endocrinology and Metabolism 200590 4930-4935. 
13 Wolff AS, Erichsen MM, Meager A, Magitta NF, Myhre AG, Bollerslev J, Fougner KJ, Lima K, Knappskog PM \& Husebye ES. Autoimmune polyendocrine syndrome type 1 in Norway: phenotypic variation, autoantibodies, and novel mutations in the autoimmune regulator gene. Journal of Clinical Endocrinology and Metabolism 200792 595-603.

14 Pearce SH, Cheetham T, Imrie H, Vaidya B, Barnes ND, Bilous RW, Carr D, Meeran K, Shaw NJ, Smith CS, Toft AD, Williams G \& Kendall-Taylor P. A common and recurrent 13-bp deletion in the autoimmune regulator gene in British kindreds with autoimmune polyendocrinopathy type 1. American Journal of Human Genetics $1998631675-1684$.

15 Lekanne Deprez RH, Fijnvandraat AC, Ruijter JM \& Moorman AF. Sensitivity and accuracy of quantitative real-time polymerase chain reaction using SYBR green I depends on cDNA synthesis conditions. Analytical Biochemistry 2002 307 63-69.

16 Livak KJ \& Schmittgen TD. Analysis of relative gene expression data using real-time quantitative PCR and the 2(-Delta Delta C(T)) method. Methods 200125 402-408.

17 Boe Wolff AS, Oftedal B, Johansson S, Bruland O, Lovas K, Meager A, Pedersen C, Husebye ES \& Knappskog PM. AIRE variations in Addison's disease and autoimmune polyendocrine syndromes (APS): partial gene deletions contribute to APS I. Genes and Immunity 20089 130-136.

18 den Dunnen JT \& Antonarakis SE. Nomenclature for the description of human sequence variations. Human Genetics 2001 $109121-124$.

19 Saugier-Veber P, Drouot N, Wolf LM, Kuhn JM, Frebourg T \& Lefebvre $\mathrm{H}$. Identification of a novel mutation in the autoimmune regulator (AIRE-1) gene in a French family with autoimmune polyendocrinopathy-candidiasis-ectodermal dystrophy. European Journal of Endocrinology $2001 \mathbf{1 4 4} 347-351$.

20 Faustino NA \& Cooper TA. Pre-mRNA splicing and human disease. Genes and Development 200317 419-437.

21 Heino M, Scott HS, Chen Q, Peterson P, Maebpaa U, Papasavvas MP, Mittaz L, Barras C, Rossier C, Chrousos GP, Stratakis CA, Nagamine K, Kudoh J, Shimizu N, Maclaren N, Antonarakis SE \& Krohn K. Mutation analyses of North American APS-1 patients. Human Mutation 199913 69-74.

22 Heino M, Peterson P, Kudoh J, Shimizu N, Antonarakis SE, Scott HS \& Krohn K. APECED mutations in the autoimmune regulator (AIRE) gene. Human Mutation 2001 18 205-211.

23 Meloni A, Fiorillo E, Corda D, Perniola R, Cao A \& Rosatelli MC. Two novel mutations of the AIRE protein affecting its homodimerization properties. Human Mutation 200525319.

24 Stolarski B, Pronicka E, Korniszewski L, Pollak A, Kostrzewa G, Rowinska E, Wlodarski P, Skorka A, Gremida M, Krajewski P \& Ploski R. Molecular background of polyendocrinopathy-candidiasis-ectodermal dystrophy syndrome in a Polish population: novel AIRE mutations and an estimate of disease prevalence. Clinical Genetics 200670 348-354.
25 Wang CY, Davoodi-Semiromi A, Huang W, Connor E, Shi JD \& She JX. Characterization of mutations in patients with autoimmune polyglandular syndrome type 1 (APS1). Human Genetics $1998103681-685$.

26 Perheentupa J. Autoimmune polyendocrinopathy-candidiasisectodermal dystrophy (APECED). Hormone and Metabolic Research 199628 353-356.

27 Cihakova D, Trebusak K, Heino M, Fadeyev V, Tiulpakov A, Battelino T, Tar A, Halasz Z, Blumel P, Tawfik S, Krohn K, Lebl J \& Peterson P. Novel AIRE mutations and P450 cytochrome autoantibodies in Central and Eastern European patients with APECED. Human Mutation 200118 225-232.

28 Bjorses P, Halonen M, Palvimo JJ, Kolmer M, Aaltonen J, Ellonen P, Perheentupa J, Ulmanen I \& Peltonen L. Mutations in the AIRE gene: effects on subcellular location and transactivation function of the autoimmune polyendocrinopathy-candidiasis-ectodermal dystrophy protein. American Journal of Human Genetics 200066 378-392.

29 Soderbergh A, Rorsman F, Halonen M, Ekwall O, Bjorses P, Kampe O \& Husebye ES. Autoantibodies against aromatic L-amino acid decarboxylase identifies a subgroup of patients with Addison's disease. Journal of Clinical Endocrinology and Metabolism $2000 \mathbf{8 5}$ 460-463.

30 Perheentupa J. APS-I/APECED: the clinical disease and therapy. Endocrinology and Metabolism Clinics of North America 200231 295-320 (vi).

31 De Luca F, Valenzise M, Alaggio R, Arrigo T, Crisafulli G, Salzano G, Cervato S, Mariniello B, Lazzarotto F \& Betterle C. Sicilian family with autoimmune polyendocrinopathy-candidiasis-ectodermal dystrophy (APECED) and lethal lung disease in one of the affected brothers. European Journal of Pediatrics, 2008 (In Press) DOI: $10.1007 / \mathrm{s} 00431-008-0668-3$.

32 Dubois N, Tardivel I, Kajosaari M, Vialettes B \& Carel JC. Autoimmune bronchiolitis is a life threatening component of autoimmune polyendocrine syndrome type 1 (APS-1). Hormone Research $2007 \mathbf{6 8} 61$.

33 Halonen M, Eskelin P, Myhre AG, Perheentupa J, Husebye ES, Kampe O, Rorsman F, Peltonen L, Ulmanen I \& Partanen J. AIRE mutations and human leukocyte antigen genotypes as determinants of the autoimmune polyendocrinopathy-candidiasis-ectodermal dystrophy phenotype. Journal of Clinical Endocrinology and Metabolism $2002872568-2574$.

34 Kishi M, Tsukada T, Shimizu S, Futami H, Ito Y, Kanbe M, Obara T \& Yamaguchi K. A large germline deletion of the MEN1 gene in a family with multiple endocrine neoplasia type 1. Japanese Journal of Cancer Research $1998 \mathbf{8 9} 1-5$.

35 Gazulla AJ, Benavente AI, Ricoy C Jr \& Madero BP. Myopathy with trabecular fibers associated with familiar autoimmune polyglandular syndrome type 1. Neurología 200520 702-708.

Received 4 July 2008

Accepted 9 July 2008 